\title{
New brachyuran crabs from the Aptian-Albian Romualdo Formation, Santana Group of Brazil: Evidence for a Tethyan connection to the Araripe Basin
}

Ludmila A.C. Prado, Javier Luque, Alcina M.F. Barreto, and A. Richard Palmer

Acta Palaeontologica Polonica 63 (4), 2018: 737-750 doi:https://doi.org/10.4202/app.00480.2018

Despite the exceptional palaeontological richness of the renowned Santana Group from the Early Cretaceous Araripe Basin of Brazil, only one specimen of true crabs (Brachyura) has been discovered to date. Here we present two new genera and species of brachyuran crabs from the upper Aptian-lower Albian Romualdo Formation of the Santana Group, represented by 30 specimens from several localities across the Araripe Basin in the state of Pernambuco, Brazil. One taxon, Exucarcinus gonzagai Prado and Luque gen. et sp. nov., is similar to several endemic stem raninoidans (Orithopsidae) from the late Aptian and early Albian of Colombia and the USA, respectively, while Romualdocarcinus salesi Prado and Luque gen. et sp. nov., seems to be closer to "higher" true crabs (Eubrachyura) from the Cenomanian of Spain. The presence of taxa similar to those from the mid-Cretaceous of northern South America, southern North America, and western Europe, reinforces the view of a Tethyan marine influence in Araripe during the breakup of South America and Africa, and adds to the growing data that suggest a generic and specific degree of endemism of true crabs in tropical South America during the mid-Cretaceous.

Key words: Decapoda, Eubrachyura, Raninoida, Exucarcinus, Romualdocarcinus, Cretaceous, South America.

Ludmila A.C. Prado [prado.lac@ gmail.com; ORCID ID:

http://orcid.org/0000-0002-9842-7074] and Alcina Barreto [alcinabarreto@gmail.com

], Departamento de Geologia, Centro de Tecnologia e Geociências, Universidade

Federal de Pernambuco, 1235, 50740-533, Recife, Pernambuco, Brazil. Javier Luque [luque@ualberta.ca ; ORCID ID: http://orcid.org/0000-0002-4391-5951], Department of Biological

Sciences, University of Alberta, Edmonton, Alberta T6G 2E9, Canada and

Smithsonian Tropical Research Institute, Balboa-Ancón 0843-03092, Panamá,

Panamá A. Richard Palmer [rich.palmer@ualberta.ca], Department of Biological Sciences, University of Alberta, Edmonton, Alberta T6G 2E9, Canada. 
This is an open-access article distributed under the terms of the Creative Commons

Attribution License (for details please see creativecommons.org), which permits unrestricted use, distribution, and reproduction in any medium, provided the original author and source are credited.

Forif Full text $(1,065.1 \mathrm{kB})$ 